Н.И. Тапильская ${ }^{1}$ С.А. Карпеев², С.Н. Гайдуков

1 ГБОУ ВПО «Санкт-Петербургский государственный педиатрический медицинский университет» Минздрава России

94100, Санкт-Петербург, Литовская ул., д. 2

2 ФГБУ «Консультативно-диагностический центр с поликлиникой» Управления делами Президента РФ

197110, Санкт-Петербург, Морской проспект, д. 3

Обзор научных исследований, посвященных хроническому эндометриту, позволяет сделать вывод, что контаминированный микроорганизмами эндометрий при наличии подтвержденного субклинического воспаления является причиной, приводящей к снижению фертильности. Хроническое субклиническое воспаление эндометрия нередко ассоциировано с генитальным эндометриозом, что, вероятнее всего, является причиной аномальных маточных кровотечений. Обнаружение того или иного микробного агента при эндометрите в рутинной амбулаторной практике не является обязательным, так как мировой опыт, включающий научные исследования с высоким уровнем доказательности, свидетельствует о целесообразности эмпирической терапии, основанной на минимальных клинических критериях, ибо в противном случае последствия для репродуктивной системы могут быть непоправимы. Превентивная антибактериальная терапия в преконцепции у пациенток с бесплодием, привычным невынашиванием беременности является эсрсективным способом просрилактики репродуктивных потерь.

Ключевые слова: хроническая воспалительная болезнь матки, антибактериальная терапия.

Контактная информация: tapnatalia@yandex.ru. Вестник дерматологии и венерологии 2015; (2): 130_138.

\title{
ustification of the efficacy of antibacterial therapy for the treatment of chronic endometritis
}

\author{
N.I. Tapilskaya ${ }^{1}$, S.A. Karpeyev², S.N. Gaidukov ${ }^{1}$
}

${ }^{1}$ St. Petersburg State Pediatric Medical University (State Budgetary Educational Institution for Higher Professional education), Ministry of Healthcare of the Russian Federation

Litovskaya str., 2, St. Petersburg, 194100, Russia

2 «Konsul'tativno-diagnosticheskij centr s poliklinikoj» Upravlenija delami Prezidenta RF Morskoy Prospekt, 3, St. Petersburg, 197110, Russia

A review of studies on chronic endometritis enables the authors to conclude that bacterially contaminated endometrium is the reason causing reduced fertility in case of confirmed subclinical inflammation. Chronic subclinical inflammation of the endometrium is often associated with genital endometriosis, which apparently leads to abnormal uterine bleedings. The identification of a microbial agent in case of endometritis in the routine outpatient practice is not mandatory because global experience including high-level evidence-based studies confirms the expediency of an empirical therapy based on minimum clinical criteria; otherwise, there may be irreversible consequences for the reproductive system. A preventive antibacterial therapy during the pre-conception period in infertile patients suffering from recurrent miscarriages is an efficient method to prevent reproductive losses.

Key words: chronic endometritis, antibacterial therapy.

Corresponding author: tapnatalia@yandex.ru. Vestnik Dermatologii i Venerologii 2015; 2: 130_138. 
Хроническая воспалительная болезнь матки имеет шифр N71.1 в Международной классификации болезней 10-го пересмотра и, как любая нозологическая форма, претендует на стандартизацию методов диагностики и стратификацию терапии.

В 2012 г. в авторитетном журнале American Jornal Obstetrics and Gynecology была опубликована статья под названием «Субклиническое воспалительное заболевание органов малого таза и бесплодие», представляющая результаты исследования, выполненного при поддержке Национальных институтов здоровья (National institutes of health (NIH)) США. Это исследование было экономически обосновано тем фрактом, что в США страдают бесплодием 7 млн женщин репродуктивного возраста, а затраты на лечение составляют 12 тыс. долларов на один цикл экстракорпорального оплодотворения (ЭКО). Исследователи сделали вывод о том, что контаминированный эндометрий при наличии подтвержденного субклинического воспаления является причиной, приводящей к снижению фрертильности [1].

На Международном конгрессе в Барселоне в 2007 г. был достигнут консенсус ставить диагноз и лечить хронический эндометрит у всех женщин, перенесших хотя бы одну регрессирующую беременность. Среди пациенток с диагнозом «бесплодие», длительно и неудачно леченных всеми доступными методами, включая вспомогательные репродуктивные технологии, хронический эндометрит диагностируется у 60\% [2]. В новой классификации причин патологических маточных кровотечений FIGO (International federation of gynecology and obstetrics, Международная федерация акушеров и гинекологов) PALM-COEIN патология эндометрия инфекционного генеза является одной из причин аномального маточного кровотечения [3]. В строме полипа эндометрия определяются клетки - маркеры воспаления. У 90\% пациенток с диагностированными микрополипами эндометрия хронический эндометрит подтверждается гистологически [4].

Научные достижения нового десятилетия меняют существующую парадигму, постулатом которой является идея о том, что полость матки является стерильным компартментом верхних отделов генитального тракта. Однако сегодня мировое научное сообщество ставит перед собой цель определиться с выбором таксономических групп микроорганизмов, нарушающих гомеостаз того или иного органа, в том числе и репродуктивного, и определить, что клинически представляет болезнь.

В клиническом исследовании РЕАСН, объединившем 13 центров и 808 пациенток, у которых перед началом лечения воспалительных заболеваний органов малого таза (ВЗОМТ), согласно протоколу CDC (Centers for disease control and prevention, Центры по контролю и профилактике заболеваний), была выпол- нена биопсия эндометрия и материал был подвергнут криоконсервации. Пациентки находились под наблюдением в течение 3 лет. В случаях диагностирования бесплодия, внематочной беременности, синдрома тазовой боли образцы эндометрия размораживались и исследовались методом полимеразной цепной реакции (ПЦР) на наличие инфекционных агентов. В 14\% случаев в образцах эндометрия была идентифицирована отнесенная мировым сообществом микробиологов к абсолютным патогенам Mycoplasma genitalium. По итогам исследования C. Haggerty L. и соавт. был сделан вывод о том, что наличие данного возбудителя в эндометрии повышает риск развития эндометрита в 13 раз [5].

В 2013 г. на XX Всемирном конгрессе ISSTDR (14-м IUSTI) американские коллеги доложили новые результаты анализа микробных изолятов, полученных из тканей эндометрия при подтвержденном хроническом эндометрите и при неизмененном эндометрии [6].

Итак, сегодня трудно отрицать тот фракт, что именно микробные агенты выступают триггером, запускающим механизмы иммунного, гормонального, гемостазиологического дисбаланса, нарушающего нормальное фрункционирование ткани эндометрия. Одним из ключевых моментов, проливающих свет на то, почему присутствие инфекционного агента в полости матки далеко не у всех пациентов приводит к развитию воспалительной реакции, является признание двух разных событий: контаминация полости матки микроорганизмами и их инвазия в строму эндометрия [7].

«Золотым стандартом» диагностики хронического эндометрита, рекомендованным CDC, является морфологическое исследование эндометрия, которое выполняется путем аспирационной биопсии вакуумной кюреткой Piple в амбулаторных условиях. Вопрос об обязательном выявлении того или иного микробного агента в рутинной амбулаторной практике не имеет положительного ответа, так как мировой опыт, включающий научные исследования с высоким уровнем доказательности, демонстрирует необходимость эмпирической терапии, основанной на минимальных клинических критериях, ибо в противном случае последствия для репродуктивной системы могут быть непоправимы. Клиницисту важно понимать, что только с помощью программы вспомогательных репродуктивных технологий без анализа причин, вызвавших бесплодие, невозможно ожидать положительного результата в плане наступления и пролонгирования беременности.

Исследования, выполненные на европейском и американском континентах в течение последних 5 лет, доказывают неоспоримое присутствие микробных агентов, контаминирующих полость матки не только пациенток с диагнозом бесплодие, но и пациенток с привычной потерей беременности. Так, в пилотном исследовании итальянских авторов из 2190 пациенток 
были отобраны 438 женщин с гистероскопическими признаками хронического эндометрита, из которых, в свою очередь, у 188 (42,9\%) имели место диссункциональные маточные кровотечения, у 163 (37,2\%) - бесплодие, у 42 (9,6\%) - эхографические признаки полипа эндометрия, у 27 (6,2\%) - субмукозная миома, у $18(4,1 \%)$ - подозрение на аномалии мочеполовой системы. Процент иноекционных агентов, выявленных во влагалище и в эндометрии у пациенток с хроническим эндометритом, составил 58,0 и 73,1\% соответственно по сравнению с 5,0 и 41,0\% в группе сравнения $(n=100)$ (отношение шансов (ОШ) для эндометрия 51,5 при 95\% доверительном интервале (ДИ) от 19,6 до 95,9; $p<0,000001)$. В эндометрии у пациенток основной группы были выявлены Streptococcus spp. (122 случая), Enterococcus faecalis (62 случая), Escherichia coli (50 случаев), Ureaplasma spp. (44 случая), Staphylococcus spp. (20 случаев), причем максимальная дискордантность наблюдалась в отношении стафилококковой, энтерококковой и хламидийной инфекций [8]. E. Cicinelli и соавт. при обследовании пациенток с гистероскопическими признаками хронического эндометрита выявили явную дискордантность в микробиологическом отделяемом из различных отделов генитального тракта (влагалище, цервикальный канал, эндометрий). Диагноз хронического эндометрита в основной группе $(n=181)$, куда вошли пациентки с гистероскопическими признаками данного заболевания, был подтвержден гистологически у 92,8\%, патогенные и/или условно-патогенные микроорганизмы выявлялись у $74,6 \%$, тогда как в контрольной группе $(n=100)$ частота гистологического подтверждения хронического эндометрита составила 6\%, эндометриальные культуры были позитивны в 5\% (ОШ = 55,8; 95\% ДИ 20,2$166,4 ; p<0,000001)$. Однако конкордантность между отделяемым из канала шейки матки и эндометрием у пациенток основной группы составила 48,3\% для условно-патогенной микрофлоры, 100\% - для хламидийной инфекции и 58,3\% - для U. urealyticum, конкордантность между отделяемым из влагалища и эндометрием для условно-патогенной микрофрлоры составила 50,2\%, для хламидийной инфекции - 16,7\% и для U. urealyticum - 48,8\%. Причем частота выявления аэробных микроорганизмов (E. coli, Streptococcus spp., Staphylococcus spp., E. faecalis) в слизистой эндометрия была значительно выше, чем в цервикальном канале и влагалище [9]. В более позднем и более емком $(n=404)$ проспективном исследовании тех же авторов при выполнении диагностической гистероскопии у пациенток без клинических проявлений проводилось изолированное бактериологическое исследование отделяемого из цервикального канала и эндометрия. Общая конкордантность между отделяемым из канала шейки матки и эндометрием составила всего 33\% в пользу эндометрия. Причем наиболее часто (в 69\% всех позитивных случаев) в эндометрии выявлялась условно-патогенная микробиота, в частности стрептококки - в 27\%, кишечная фрлора (E. faecalis, E. coli) в $31 \%$, U. urealyticum - 10\%, Mycoplasma spp. - 0,2\% [10]. В недавнем исследовании продемонстрирована колонизация микроорганизмами с образованием биопленок не только эндометрия, но и эпителия маточных труб [11].

Следует отметить, что выявление инфекционных агентов в эндометрии во всех исследованиях проводилось высокотиражируемыми в клинико-лабораторной практике методами: микроскопическими, бактериологическими и молекулярно-генетическими. Однако использование бурно развивающихся расширенных молекулярно-генетических методов и хроматографической масс-спектрометрии как эфрфективных высокоинформативных методов анализа и установления качественного и количественного строения индивидуальных органических соединений расширяет наши представления о природе патогена и увеличивает точность диагностики. Микробиологи всего мира накапливают изоляты нуклеиновых кислот, не принадлежащие к известным на сей момент таксономическим единицам, получившим в настоящее время название «патогенов, ассоциированных с заболеваниями человека» или «изолятов, ассоциированных с инфекциями человека» [12].

Оригинальные исследования, появившиеся в печати в текущем году, подтверждают концепцию назначения антибактериальной терапии у пациенток с диагнозом хронического эндометрита с анамнезом привычной потери плода не только исключительно при идентификации инфекционного агента, но и на основании клинических данных. Так, E. Cicinelli и coавт. назначали два курса антибактериальной терапии в случае отсутствия критериев клинической излеченности согласно данным гистероскопического обследования. При выявлении уреаплазменной инфекции вторым курсом назначался антибактериальный препарат джозамицин в дозе 1,0 г в сутки в течение 14 дней. В случае обнаружения грамположительных микроорганизмов - аммоксицилин + клавуроновая кислота по 1,0 г 2 раза в сутки в течение 8 дней. чрезвычайно важным явился тот фракт, что у пациенток с диагнозом хронического эндометрита в случае негативных культур микроорганизмов назначалась эмпирическая антибактериальная терапия, которая, согласно стандартам CDC, включала применение цестриаксона, доксициклина и метронидазола в течение 14 дней. В группе пациенток, где было достигнуто как клиническое, так и микробиологическое излечение, у 78\% пациенток в течение года наступила беременность, которая закончилась рождением живых детей [13].

D. McQueen из Чикагского университета в похожем по дизайну исследовании, опубликованном в 2014 г., делают вывод, что назначение одного курса 
антибактериальной терапии у пациенток с привычной потерей плода с подтвержденным диагнозом хронического эндометрита позволяет добиться клинического выздоровления в 94\% случаев, а при проведении двух курсов антибактериальной терапии - практически в 100\% [14].

A. Takebayashi и соавт. в проспективном сравнительном исследовании $(n=71)$, продолжавшемся в течение 10 лет (2002-2012 гг.), оценили уровень распростаненности хронического эндометрита у пациенток с эндометриозом. По поводу распространенного генитального эндометриоза или сопутствующего гинекологического заболевания (миома матки) была выполнена гистерэктомия. С целью подтверждения диагноза хронического эндометрита, согласно стандартам CDC, в тканях эндометрия определялась экспрессия синдикана-1. Хронический эндометрит был диагностирован у 52,94\% пациенток с эндометриозом и у $27,02 \%$ пациенток в группе сравнения ( $p=0,031)$ [15]. В сравнительном исследовании по типу “случай - контроль» среди пациенток с генитальным эндометриозом $(n=128)$, получавших терапию аналогами гонадотропин-рилизинггормона (а-ГнРГ), установлен высокий удельный вес персистенции условно-патогенной микробиоты в эндометрии у женщин с эндометриозом, причем лечение а-ГнРГ увеличивало частоту контаминации эндометрия. При количественном сравнении количество колониеобразующих единиц E. coli, Gardnerella, $\alpha$-стрептококков, энтерококков было значительно выше в образцах, полученных из эндометрия женщин, страдающих эндометриозом, по сравнению с контрольной группой ( $p<0,05$ для каждого бактериального агента). Таким образом, установлено, что у пациенток с генитальным эндометриозом снижена колонизационная резистентость нижних отделов генитального тракта, что коррелирует с высокой частотой и степенью микробной колонизации эндометрия. Полученные данные подтвердили наличие субклинического воспаления эндометрия у женщин с эндометриозом [16].

Подтверждение наличия субклинического воспаления эндометрия у пациенток с аденомиозом проливает свет на причину аномальных маточных кровотечений у данного контингента пациенток.

Осознание мировым сообществом клиницистов необходимости проведения антибактериальной терапии у пациенток с диагнозом хронического эндометрита в случае привычной потери беременности, неудач ЭКО крайне значимо, так как меняются неверные представления среди врачей в нашей стране: хронический эндометрит - аутоиммунный процесс, который надо лечить с помощью иммуномодуляторов, адаптогенов, гестагенов, и это довольно не полный перечень препаратов, не относящихся к воздействию на этиологический фактор заболевания.
В проспективном исследовании, продолжавшемся с 2001 по 2007 г. и направленном на изучение состояния эндометрия у пациенток с повторными неудачными попытками ЭКО при условии наличия эмбрионов хорошего качества, была выполнена биопсия эндометрия до и после лечения антимикробными препаратами. Всем пациенткам, подвергающимся биопсии эндометрия, были выполнены кариотипирование, определение уровня антифосфролипидных антител, гистероскопия, ультрасонография органов малого таза - при выявлении патологии пациенты в исследование не включались. При иммуногистохимическом исследовании биоптатов эндометрия с целью изучения экспрессии в тканях эндометрия маркера плазматических клеток (CD138) у 33,3\% пациенток был диагностирован хронический эндометрит. Пациентки с верифицированным диагнозом получали антибактериальную терапию первой или второй линии в зависимости от данных повторной биопсии, в результате чего процент наступления клинической беременности в следующем протоколе вспомогательных репродуктивных технологий составил 20\% [17].

Используемые в широкой клинико-лабораторной практике иммуногистохимические маркеры хронического эндометрита (CD16, CD20, CD56, CD138), бесспорно, имеют диагностическое и прогностическое значение, и именно их обнаружение является исторически обусловленным следствием достаточно высокой специфичности и высокой степени обоснованности использования в диагностике данной патологии. Однако, в сущности, по причине непрекращающегося иммунопатологического процесса MALT-системы генитального тракта (MALT - mucosa-associated lymphoid tissue) при хроническом эндометрите фенотип эндометрия качественно меняется. Так, при сравнении профиля экспрессии 25 генов эндометрия, принимающих участие в воспалении, пролиферации, клеточной диффреренцировке и апоптозе во время «окна имплантации», определяемых методом RT-PCR, при хроническом эндометрите отмечалась, с одной стороны, выраженная сверхэкспрессия IGFBP1 (Insulin-like growth factor-binding protein 1; инсулиноподобный фактор, связывающий белок 1) $(p=0,011), \operatorname{Bcl} 2(p=0,006)$ и $\operatorname{BAX}(p=0,011)$, с другой стороны, выраженная даун-регуляция IL-11 ( $p=0,001)$, CCL4 ( $p=0,016)$, IGF1 $(p=0,001)$ и CASP8 $(p=0,015)$, что объясняет высокую частоту гиперпластических процессов и нарушение динамики имплантации, связанное с изменением рецептивных свойств эндометрия, у пациенток с хроническим эндометритом [18]. Учитывая дисбаланс цитокинового профиля с преобладанием провоспалительных цитокинов, делаются попытки валидизировать в качестве скрининговых неинвазивных методов диагностики хронического эндометрита определение уровня IL-6 и TNF $\alpha$ в менструальной крови [19].

В качестве примера, подтверждающего фракт влияния микробного агента на экспрессию генов, в част- 
ности, транскрибирующихся в эндометрии во время «окна имплантации», можно привести персистенцию E. coli в эндометрии: данный микроорганизм является мощным триггером нарушения специфического профиля транскрипционной активности генов. В то же время известно, что количественный и качественный профиль вовлеченных в воспалительный ответ генов строго детерминирован. В эксперименте на селекционно выведенных кобылицах, отличающихся различной чувствительностью к изучаемому микроорганизму, при инокуляции в эндометрий культуры E. coli количественный профриль экспрессии провоспалительных (IL-1 $\beta$, IL-6, IL-8, TNF $\alpha$ ) и противовоспалительных (IL-10, IL-1RA) цитокинов в разных группах животных значительно различался: разница в уровне мРНК исследуемых генов достигала 2-20-кратных значений [20].

Как следствие, в результате персистирующего повреждения эндометрия инфекционным агентом напрямую или посредством метаболитов возникают множественные вторичные морфофункциональные изменения, нарушающие циклическую биотрансформацию и рецептивность слизистой оболочки тела матки, что, очевидно, связано именно с изменением профиля генов [21].

В экспериментальной работе на культуре клеток стромы эндометрия было продемонстрировано, что при нокауте гена синдекана-1 (CD138) значительно изменяется цитокиновый профиль клеток, на основании чего авторы сделали вывод, что синдекан является кофрактором для многих цитокинов и хемокинов, принимающих участие в хемокинопосредованном ангиогенезе и имплантации эмбриона [22]. Шеддинг эктодомена синдекана-1 способен изменять степень воспалительного ответа путем минимизации количества эфффекторных молекул, которые обеспечивают и регулируют полноценный воспалительный ответ, за счет их связывания с гепарансульфатом. При гиперэкспрессии синдекана-1 нарушается процесс связывания антигенов с Толл-подобными рецепторами дендритных клеток, а также происходит изменение взаимодействия интегринов лейкоцитов и эндотелиальных молекул адгезии ICAM-1 и VCAM-1, что нарушает полноценность иммунного ответа и приводит к персистенции функционально аномальных лейкоцитов. На мышиной модели аллергического заболевания эктодомены синдекана-1 ингибируют именно Th2-иммунный ответ, в результате чего нарушается иммунная толерантность организма к собственным структурам. С другой стороны, у мышей, нокаутированных по гену синдекана-1, происходит дисбаланс специфического Т-клеточного иммунного ответа на патоген еще и за счет выраженного смещения в сторону Th2-ответа. Таким образом, при хроническом эндометрите вследствие, в частности, сверхэкспрессии синдекана-1 развивается дисбаланс Т-клеточного иммунитета с пре- обладанием Th1-клона, что нарушает иммунную толерантность к трофобласту эмбриона [23].

Синдекан-1 как представитель семейства гепарансульфат протеогликанов играет одну из решающих ролей в распространении от клетки к клетке вируса простого герпеса типа 1: при сверхэкспрессии данного гликопротеина происходит качественное изменение свойств клеточной стенки и эндоцитоззависимое (за счет слияния вирусных гликопротеинов с белками клеточной стенки хозяина и последующего слияния вирусной оболочки с клеточной мембраной) распространение вирусной инфекции, что является одним из основных механизмов поддержания пожизненной латентной, персистирующей вирусной инорекции [24]. Одно из основных мест в новых стратегиях противогерпетической вируссупрессивной терапии занимают именно протеогликановые рецепторы как мишени, воздействие на которые позволит предотвратить «линейное» распространение вируса в тропных тканях [25].

Таким образом, персистирующие микробные агенты в эндометрии изменяют уровень экспрессии иммуномодуляторных молекул, ответственных за функциональную полноценность иммунной системы, а гиперэкспрессия синдекана-1 (CD138) способствует изменению рецептивных свойств эндометрия, цитокинового профиля эндометрия, активации патологического ангиогенеза, супрессии эффректорного звена местного иммунитета и, таким образом, является благоприятным фрактором для распространения и персистенции вирусной инфекции.

При изучении биоптатов эндометрия, полученных от бесплодных женщин с неудачными попытками ЭКО, было установлено достоверное повышение секреции $\lg \mathrm{M}$, IgA, IgG и сверхэкспрессия $\operatorname{lgG}_{2}$ у пациенток с лабораторно подтвержденным хроническим эндометритом в сравнении с пациентками без такового [26].

В крупном исследовании $(n=597)$ японских ученых у пациенток с повторными неудачными попытками ЭКО показано, что после лечения антибактериальными препаратами происходила нормализация экспрессии ММП-2 и -9, отвечающих за инвазию трофобласта, что в последующем значительно повышало частоту наступления беременности в протоколах ЭКО (42\% против 26\% в группе сравнения) и снижало риск возникновения кровотечений в ранние сроки беременности (28,5\% против 36,5\% в группе сравнения) [27].

Проведено проспективное исследование $(n=262)$ у пациенток с многократными неудачными попытками ЭКО, у 60 из них имелось морфологическое подтверждение диагноза. Из 202 оставшихся пациенток гистероскопические признаки хронического эндометрита были у 66,3\%, иммуногистохимические - у 43,6\%. Пациенты с подтвержденным хроническим эндометритом были разделены на две группы, одна из которых получала комбинированную антибактериальную те- 
рапию. У женщин с гистероскопическими признаками хронического эндометрита, получавших антибактериальную терапию, в следующем протоколе переноса эмбрионов частота наступления беременности была достоверно выше (29,3 против 11,1\%, $p=0,031)$ [28].

В работе J. Espinoza и соавт., поддержанной грантом правительства США, авторы ставят принципиальный вопрос о необходимости назначения антибактериальной терапии в преконцепции у пациенток с преждевременными родами в анамнезе на основании трудностей в проведении микробиологических исследований эндометрия традиционными методами и ограниченности существующих микробиологических методов, а также потенциальных возможностей молекулярной микробиологии в изучении микробиома эндометрия с целью снижения репродуктивных потерь. Во время беременности происходят изменения вирулентности инфекционного агента (например, способность бактерии к высвобождению из биопленок), что может привести к реактивации инфекции и индукции преждевременных родов [7].

В проспективном исследовании, выполненном с мая по октябрь 2011 г., у беременных в возрасте от 19 до 42 лет P. Aydogan и соавт. установлена положительная корреляция между выявленной уреаплазменной и/или микоплазменной инфекцей в посевах отделяемого из цервикального канала и патологической (полное или неполное предлежание плаценты) плацентацией (ОШ = 5,06; 95\% ДИ 0,75-33,77; $p=0,02, r=0,442)$, а также увеличением объема кровопотери во время кесарева сечения (ОШ = 1,20; $95 \%$ ДИ 0,74-1,92; $p=0,48, r=0,145)$ [29].

Итак, возвращаясь к вопросу о лечении пациенток с установленным диагнозом хронического эндометрита, следует уточнить, что подразумевает термин «эмпирически обоснованная противомикробная терапия».

Эмпирическая противомикробная терапия предполагает:

- эпидемиологические данные о возбудителе/возбудителях;

данные о чувствительности возбудителя/возбудителей к назначаемому курсу противомикробной терапии;

обоснованные положительные эффректы выбранного курса противомикробной терапии;

применение достаточного курса и выбор оптимальных доз;

использование оригинальных препаратов.

В отличие от многих других антибиотиков макролиды хорошо проникают в клетки и создают высокие концентрации в гранулоцитах, моноцитах, альвеолярных макрофрагах, фрибробластах. Системному противовоспалительному действию макролидов сегодня придается крайне важное значение, например при лечении острых инфекций дыхательных путей. Воздействие макролидов на иммунную систему начинает- ся с подавляющего влияния на миграцию и диапедез активированных бактериальными антигенами лейкоцитов в инфекционном очаге, благодаря чему уменьшается объем вовлеченных в воспаление тканей, что впоследствии может привести к индуративным изменениям. Причем в настоящее время это считается настолько значимым с клинической точки зрения, что создаются иммунотропные макролидные соединения (12-членные), вообще не проявляющие антимикробной активности, но при этом обладающие противовоспалительным свойством [30]. В эксперименте 14-, 15-,16-членные макролидные антибиотики демонстрируют иммуномодулирующие свойства: усиливают фрагоцитарную активность перитонеальных макрофрагов, в дозозависимой манере увеличивают секрецию ими IL-12 и IL-18, а также, что особенно значимо для имплантации эмбриона, активируют Th2-иммунный ответ за счет усиления секреции спленоцитами IL-4. B некотором роде системное действие в отношении изменения адгезивных свойств клеток способно повлиять на адгезию патогенов и, следовательно, дальнейшую колонизацию тканей [31]. Также макролиды ингибируют активность фрерментных систем некоторых инфекционных агентов, что сопровождается подавлением образования биопленок. Именно антибиопленочное действие обеспечивает клиническую эффективность макролидов при хроническом воспалении [32]. Макролиды за счет прямого бактериостатического действия после селективной кумуляции также ингибируют фосфрорилирование ERK1/2-киназы и активацию ядерного фактора NF-кB, что в итоге приводит к меньшей экспрессии молекул адгезии и к снижению продукции провоспалительных цитокинов, медиаторов воспаления и реактивных фрорм кислорода. Предполагается, что длительная терапия макролидами видоизменяет характер взаимодействия патогена с макроорганизмом, трансформируя процесс из инфекции в относительно доброкачественную колонизацию, при этом у некоторых больных наблюдается и эрадикация возбудителя.

С френоменом трансформации инфекции в колонизацию может быть связано нередко наблюдаемое при длительном применении макролидов более быстрое улучшение клинических и лабораторных показателей по сравнению с бактериологическими параметрами [33]. Немаловажно, что сочетание антибактериального эффректа макролидов с иммуномодулирующими и противовоспалительными свойствами конвертировалось в клинической практике в лечении хронических заболеваний дыхательных путей. Так, метаанализ профилактического применения макролидов продемонстрировал достоверное снижение риска рецидива, повторной госпитализации и смерти у пациентов с хронической обструктивной болезнью легких [34]. Таким образом, макролиды кроме бактериостатического действия демонстрируют также системные противо- 
воспалительные и иммуномодулирующие свойства, что делает их препаратами выбора в лечении заболеваний, сопровождающихся иммунопатологическими процессами.

В проспективном итальянском эпидемиологическом исследовании по изучению антибактериальной резистентности к внутриклеточным агентам, выполненном с января по август 2011 г. на достаточно крупной мультиэтнической выборке ( $n=433,331$ женщина, 102 мужчины), U. urealyticum выявлялась в 152 случаях: 41,9\% среди всех женщин и 12,7\% среди всех мужчин, включенных в исследование $\left(\chi^{2}=29,80\right.$; $p=0,0001)$, M. hominis - только в 6 случаях. В исследование включались все пациенты с симптомами уретрита, вагинита и другими жалобами, ассоциироваными с поражением мочеполовой системы (боль, частое мочеиспускание, паховая лимфоаденопатия, гематурия и др.). Критериями исключения являлись микоплазменная микстинфекция, прием антибиотиков в течение 1 мес. до включения в исследование, структурные аномалии мочеполовой системы, гомосексуализм, психиатрические расстройства. Исследуемые инфекционные агенты in vitro были в 100\% случаев чувствительны к джозамицину, в то время как относительное количество штаммов $U$. urealyticum, резистентных к ципрофллоксацину и офлоксацину, составило 66,4 и 27,6\% соответственно, а штаммов M. hominis, резистентных к азитромицину, рокситромицину и эритромицину, - 66,7, 66,7 и 100\% соответственно [35]. В крупном проспективном исследовании, продолжающемся 7 лет (2004-2011 гг.), было проанализировано 9956 биообразцов, среди которых в 1856 (18,6\%) выявлялись U. urealyticum и/или M. hominis, микстинфекция была диагностирована в 9,8\% среди всех положительных результатов. По заключению авторов, джозамицин - наиболее эффективный макролид в отношении данных внутриклеточных агентов, причем джозамицин является препаратом выбора для лечения микстинфекции [36]. Согласно протоколам химиотерапии ВЗОМТ, джозамицин демонстрирует уровень эрадикации Mycoplasma genitalium в 95,8\%, тогда как в 2014 г. уже опубликованы данные, касающиеся резистентности M. genitalium к азитромицину [37, 38].

Метаанализ 12 крупных исследований (9 проспективных и 3 ретроспективных) в популяции беременных женщин общей емкостью в 21262 наблюдения продемонстрировал роль хламидийной инфекции в акушерской и неонатальной патологии. По данным авторов, хламидийная инфекция при беременности увеличивает относительный риск преждевременных родов, рассчитанный по методу Кохрана - Мантеля - Гензеля, в 1,35 раза (95\% ДИ 1,11-1,63), низкой массы пло- да в 1,52 раза $(95 \%$ ДИ 1,24-1,87) и перинатальной смертности в 1,84 раза (95\% ДИ 1,15-2,94) [39]. Предваряя выпуск новых клинических рекомендаций по лечению уреаплазменной инфекции, необходимо отметить, что на XX Всемирном конгрессе ISSTDR (14-м конгрессе IUSTI) были сделаны выводы о возможной этиологической роли уреаплазм в развитии преждевременных родов [40].

Таким образом, понятие нормальной микробиоты различных отделов генитального тракта находится на этапе накопления научных знаний. Список репродуктивно значимых инфекций, являющихся причиной бесплодия и привычного невынашивания беременности, открыт для пополнения новыми таксономическими группами микроорганизмов. Комменсалитические взаимоотношения между микро- и макроорганизмом могут трансорормироваться не только в острое, но и в субклиническое воспаление. Степень выраженности воспалительного ответа макроорганизма, определяющегося в нарушении гомеостаза и приводящего к деструкции ткани в результате взаимодействия с микробными агентами, является строго генетически детерминированным свойством макроорганизма. Как следствие, превентивная антибактериальная терапия в преконцепции у пациенток с бесплодием, привычным невынашиванием беременности рассматривается как эфффективный способ профилактики репродуктивных потерь. Джозамицин является препаратом выбора за счет широкого спектра действия, высокой эфрективности в отношении внутриклеточных агентов и анаэробной микробиоты, благоприятного профиля безопасности, а также дополнительного системного противовоспалительного и иммуномодулирующего свойств.

Говоря о выборе макролидных антибиотиков, все большие сложности в настоящее время представляет массовое распространение генерических препаратов, характерное, в частности, для азитромицина, кларитромицина и др. Джозамицин представлен на фармацевтическом рынке в виде единственного оригинального лекарственного препарата. Таким образом, при его назначении исключен риск возникновения проблем, ассоциированных с применением генериков, в частности развития непредвиденных лекарственных реакций или недостаточной эффрективности.

Кроме того, для отечественного специалиста важно, что джозамицин включен в российские и европейские рекомендации по лечению хламидийной инфекции у беременных, а Регистр лекарственных средств РФ разрешает его применение во время всего срока гестации [41]. І | 


\section{Литература}

1. Wiesenfeld H.C., Hillier S.L., Meyn L.A., Amortegui A.J., Sweet R.L. Subclinical pelvic inflammatory diseaseand infertility. Obstet Gynecol 2012; 120: 37-43.

2. Radzinskii V.E., Dimitrova V.I., Maiskova I.Iu. Developing pregnancy. M: GEOTAR Media 2009; 196. [Радзинский В.Е. Димитрова В.И. Майскова И.Ю. Неразвивающаяся беременность. М: Геотар-Медиа 2009; 196.]

3. Munro M.G., Critchley H.O., Broder M.S., Fraser I.S.; FIGO Working Group on Menstrual Disorders. FIGO classification system (PALMCOEIN) for causes of abnormal uterine bleeding in nongravid women of reproductive age. Int $\mathrm{J}$ Gynaecol Obstet 2011; 113 (1): 3-13.

4. Cicinelli E., Tinelli R., Lepera A., Pinto V., Fucci M., Resta L. Correspondence between hysteroscopic and histologic findings in women with chronic endometritis. Acta Obstet Gynecol Scand 2010; 89 (8): 1061—5.

5. Haggerty C.L. Evidence for a role of Mycoplasma genitalium in pelvic inflammatory disease. Curr Opin Infect Dis 2008; 21 (1): 65—9.

6. Hillier S.L., Rabe L.K., Meyn L., Macio I., Trucco G., Amortegui A., Darville T., Wiesenfeld H.C. Endometrial Gardnerella vaginalis and Atopobium Vaginea are associated with histologic endometritis among women with clinically diagnosed pelvic inflammatory disease (PID). Sex Transm Infect 2013; 89 (1): A36.

7. Espinoza J, Erez O, Romero R. Preconceptional antibiotic treatment to prevent preterm birth in women with a previous preterm delivery. Am J Obstet Gynecol 2006; 194 (3): 630-7.

8. Cicinelli E., De Ziegler D., Nicoletti R., Colafiglio G., Saliani N., Resta L., Rizzi D., De Vito D. Chronic endometritis: correlation among hysteroscopic, histologic, and bacteriologic findings in a prospective trial with 2190 consecutive office hysteroscopies. Fertil Steril 2008; 89 (3): 677-84.

9. Cicinelli E., De Ziegler D., Nicoletti R., Tinelli R., Saliani N., Resta L., Bellavia M., De Vito D. Poor reliability of vaginal and endocervical cultures for evaluating microbiology of endometrial cavity in women with chronic endometritis. Gynecol Obstet Invest 2009; 68 (2): 108-15.

10. Cicinelli E., Ballini A., Marinaccio M., Poliseno A., Coscia M.F., Monno R., De Vito D. Microbiological findings in endometrial specimen: our experience. Arch Gynecol Obstet 2012; 285 (5): 1325-9.

11. Swidsinski A., Verstraelen $H_{\text {., L Lening- }}$ Baucke V., Swidsinski S., Mendling W., Halwani Z. Presence of a polymicrobial endometrial biofilm in patients with bacterial vaginosis. PLOS One 2013; 8 (1): e53997.

12. Rockx B., Winegar R., Freiberg A.N. Recent progress in henipavirus research: molecular biology, genetic diversity, animal models. Antiviral Res 2012; 95 (2): 135—49.
13. Cicinelli E., Matteo M., Tinelli R., Pinto V., Marinaccio M., Indraccolo U., De Ziegler D., Resta L. Chronic Endometritis Due to Common Bacteria is prevalent in women with recurrent miscarriage as confirmed by improved pregnancy outcome after antibiotic treatment. Reproductive Sciences 2014; 21 (5): 640_7.

14. Dana B. McQueen, M.D., Lia A. Bernardi, M.D and Mary D. Stephenson, M.D., M.Sc. Chronic endometritis in women with recurrent early pregnancy loss and/or fetal demise. Fertil Steril 2014; 101 (4): 1026-30.

15. Takebayashi A., Kimura F., Kishi Y., Ishida M., Takahashi A., Yamanaka A., Takahashi K., Suginami H., Murakami T. The association between endometriosis and chronic endometritis. PLOS One 2014; 18; 9 (2): e88354.

16. Khan K.N., Fujishita A., Kitajima M., Hiraki K., Nakashima M., Masuzaki H. Intra-uterine microbial colonization and occurrence of endometritis in women with endometriosis. Hum Reprod 2014; 29 (11): 2446-56.

17. Johnston-MacAnanny E.B., Hartnett J., Engmann L.L., Nulsen J.C., Sanders M.M., Benadiva C.A. Chronic endometritis is a frequent finding in women with recurrent implantation failure after in vitro fertilization. Fertil Steril 2010; 93 (2): $437-41$.

18. Di Pietro C., Cicinelli E., Guglielmino M.R., Ragusa M., Farina M., Palumbo M.A., Cianci A. Altered transcriptional regulation of cytokines, growth factors, and apoptotic proteins in the endometrium of infertile women with chronic endometritis. Am J Reprod Immunol 2013; 69 (5): 509-17.

19. Tortorella C., Piazzolla G., Matteo M., Pinto V., Tinelli R., Sabbà C., Fanelli M., Cicinelli E. Interleukin-6, interleukin-1 $\beta$, and tumor necrosis factor $\alpha$ in menstrual effluents as biomarkers of chronic endometritis. Fertil Steril 201; 101 (1): 242-7.

20. Christoffersen M., Woodward E., Bojesen A.M., Jacobsen S., Petersen M.R., Troedsson M.H., Lehn-Jensen $\mathrm{H}$. Inflammatory responses to induced infectious endometritis in mares resistant or susceptible to persistent endometritis. BMC Vet Res 2012; 8: 41.

21. Dewi F.N., Wood C.E., Lampe J.W., Hullar M.A., Franke A.A., Golden D.L., Adams M.R., Cline J.M. Endogenous and exogenous equol are antiestrogenic in reproductive tissues of apolipoprotein e-null mice. J Nutr 2012; 142 (10): 1829-35.

22. Baston-Büst D.M., Götte M., Janni W., Krüssel J.S., Hess A.P. Syndecan-1 knock-down in decidualized human endometrial stromal cells leads to significant changes in cytokine and angiogenic factor expression patterns. Reprod Biol Endocrinol 2010; 8: 133
23. Teng Y.H., Aquino R.S., Park P.W. Molecular functions of syndecan-1 in disease. Matrix Biol 2012; 31 (1): 3-16.

24. Karasneh G.A., Ali M., Shukla D. An important role for syndecan-1 in herpes simplex virus type-1 induced cell-to-cell fusion and virus spread. PLoS One 2011; 6 (9): e25252.

25. Antoine T.E., Park P.J., Shukla D. Glycoprotein targeted therapeutics: a new era of anti-herpes simplex virus-1 therapeutics. Rev Med Virol 2013; 23 (3): 194-208.

26. Kitaya K., Tada Y., Hayashi T., Taguchi S., Funabiki M., Nakamura Y. Comprehensive endometrial immunoglobulin subclass analysis in infertile women suffering from repeated implantation failure with or without chronic endometritis. Am J Reprod Immunol 2014; 72 (4): 386-91.

27. Yoshii N., Hamatani T., Inagaki N., Hosaka T., Inoue 0., Yamada M., Machiya R., Yoshimura Y., Odawara Y. Successful implantation after reducing matrix metalloproteinase activity in the uterine cavity. Reprod Biol Endocrinol 2013; 11: 37.

28. Yang R., Du X., Wang Y., Song X., Yang Y., Qiao J.The hysteroscopy and histological diagnosis and treatment value of chronic endometritis in recurrent implantation failure patients. Arch Gynecol Obstet 2014; 289 (6): 1363—9.

29. Aydogan P., Kahyaoglu S., Saygan S., Kaymak O, Mollamahmutoglu L, Danisman N. Does cervical ureaplasma/mycoplasma colonization increase the lower uterine segment bleeding risk during cesarean section among patients with placenta previa? A cross-sectional study. Eur Rev Med Pharmacol Sci 2014; 18 (16): 2243-7.

30. Amsden G.W. Anti-inflammatory effects of macrolides--an underappreciated benefit in the treatment of community-acquired respiratory tract infections and chronic inflammatory pulmonary conditions? J Antimicrob Chemother 2005; 55 (1): 10-21.

31. Ortega E., Escobar M.A., Gaforio J.J., Algarra I., Alvarez De Cienfuegos G. Modification of phagocytosis and cytokine production in peritoneal and splenic murine cells by erythromycin $A$, azithromycin and josamycin. J Antimicrob Chemother 2004; 53 (2): 367-70.

32. Khan S., Tøndervik A., Sletta H., Klinkenberg G., Emanuel C., Onsøyen E., Myrvold R., Howe R.A., Walsh T.R., Hill K.E., Thomas D.W. Overcoming drug resistance with alginate oligosaccharides able to potentiate the action of selected antibiotics. Antimicrob Agents Chemother 2012; 56 (10): $5134-41$.

33. Kanoh S., Rubin B.K. Mechanisms of action and clinical application of macrolides as immunomodulatory medications. Clin Microbiol Rev 2010; 23 (3): 590—615. 
34. Donath E., Chaudhry A., Hernandez-Aya L.F. Lit $\mathrm{L}$. A meta-analysis on the prophylactic use of macrolide antibiotics for the prevention of disease exacerbations in patients with Chronic Obstructive Pulmonary Disease. Respir Med 2013; 107 (9): 1385-92.

35. Leli C., Mencacci A., Bombaci J.C., D'Alò F., Farinelli S., Vitali M., Montagna P., Bietolini C., Meucci M., Perito S., Bistoni F. Prevalence and antimicrobial susceptibility of Ureaplasma urealyticum and Mycoplasma hominis in a population of Italian and immigrant outpatients. Infez Med 2012; 20 (2): 82-7.
36. De Francesco M.A., Caracciolo S., Bonfanti C., Manca N. Incidence and antibiotic susceptibility of Mycoplasma hominis and Ureaplasma ureaIyticum isolated in Brescia, Italy, over 7 years. J Infect Chemother 2013; 19 (4): 621-7.

37. Gushchin A.E., Burtsev O.A., Tyzhikhy P.G. et al. Monitoring treatment of patients with $M y c 0-$ plasma genitalium infection using PCR and NASBA in real time. Klin dermatol venerol 2009; 4: 58-63. [Гущин А.Е., Бурцев 0.А., Рыжих П.Г. и др. Мониторинг лечения пациентов с инсеекцией, вызванной Mycoplasma genitalium, с помощью методов ПЦР и НАСБД в реальном времени. Клин дерматол венерол 2009; (4): 58-63.]
38. Horner P., Blee K., Adams E. Time to manage Mycoplasma genitalium as an STI: but not with azithromycin 1 g! Curr Opin Infect Dis 2014; 27 (1): 68-74.

39. Silva M.J., Florêncio G.L., Gabiatti J.R., Amaral R.L., Eleutério Júnior J., Gonçalves A.K. Perinatal morbidity and mortality associated with chlamydial infection: a meta-analysis study. Braz J Infect Dis 2011; 15 (6): 533—9.

40. sti.bmj.com

41. Radzinskii V.E. Reproductive infectology XXI century. StatusPraesens 2013; 16 (5): 33-36. [Радзинский В.Е. Репродуктивная инфектология XXI века. StatusPraesens 2013; 16 (5): 33-36.]

об авторах:

Н.И. Тапильская - д.м.н., профессор, профессор кафедры акушерства и гинекологии, профессор кафедры онкологии ГБОУ ВПО «Санкт-Петербургский государственный педиатрический медицинский университет» Минздрава России

С.А. Карпеев - заведующий стационаром краткосрочного пребывания, ФГБУ «Консультативно-диагностический центр с поликлиникой» Управления делами Президента РФ

С.Н. Гайдуков - д.м.н., профессор, зав. кафедрой акушерства и гинекологии ГБОУ ВПО «Санкт-Петербургский государственный педиатрический медицинский университет» Минздрава России 